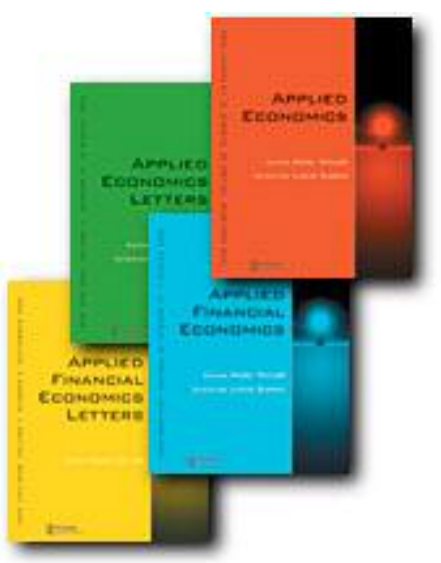

Measuring efficiency in education: an analysis of different approaches for incorporating non-discretionary inputs

\begin{tabular}{|r|l|}
\hline Journal: & Applied Economics \\
\hline Manuscript ID: & APE-06-0003.R1 \\
\hline Journal Selection: & Applied Economics \\
\hline JEL Code: & $\begin{array}{l}\text { D20 - General < D2 - Production and Organizations < D - } \\
\text { Microeconomics, I22 - Educational Finance < I2 - Education < I - } \\
\text { Health, Education, and Welfare }\end{array}$ \\
\hline Keywords: & DEA, Efficiency, Exogenous Factors, Bootstrap \\
\hline \multicolumn{2}{|l}{} \\
\hline
\end{tabular}

powered by ScholarOne

Manuscript Central ${ }^{\mathrm{TH}}$ 


\title{
"Measuring efficiency in education: an analysis of different approaches for incorporating non-discretionary inputs"
}

\begin{abstract}
Summary
Measuring efficiency in the education sector is a highly complex task. One of the reasons is that the main resource of schools (the type of students they have) lie outside of their control, which means that it must be treated differently to other factors in analysis. This study examines the different options available in the literature for incorporating non-controllable inputs in a DEA analysis in order to determine the most appropriate model for evaluating schools. Our empirical study presents the results obtained using the model proposed by Fried et. al (1999), though we use bootstrap techniques to avoid problems of bias in the estimations.
\end{abstract}

Key words: DEA, Efficiency, Exogenous Factors, Bootstrap 


\section{INTRODUCTION}

The special attention that both public authorities and the scientific community have always paid to the educational sector makes good sense if we remember that there is a strong correlation between the quality of education, measured through the results obtained in international tests, and countries' economic growth (Hanushek and Kimko, 2000, or, Barro, 2001).

A good part of research activity in recent years has been directed towards analysing the behaviour of schools by trying to measure their efficiency levels, making it necessary to relate results with resources. The analysis of efficiency in the educational field is more complex than in other production sectors for various reasons. These include the difficulty of measuring output, medium term effects or the fact that the production function is unknown. Since the publication of the Coleman Report (1966), it has also been recognized that the effects of certain exogenous factors on output, such as the pupils' socio-economic characteristics or their abilities, may be greater than others typical of the educational process (teachers, cost per student, class sizes, etc.) If we take into account that these factors are outside the control of schools the complicated task of evaluating the efficiency of their performance becomes more difficult.

A review of the literature in this area enables us to verify that, in addition to the accepted significance of these exogenous factors, there are many different options for including them in evaluations. While the first studies considered controllable and non-controllable inputs in the same way (Bessent et. al, 1982), more recent studies include both inputs together in a single stage, though treating them differently (Ruggiero, 1998). The evaluation process in other studies comprises several stages with the objective of treating the special nature of these factors in an appropriate way (Ray, 1991; McCarty and Yaisawarng, 1993; Simar and Wilson, 2003). Within the multi-stage options, there are theoretical 
propositions that have not yet been applied in the educational field (Fried et. al, 1999 or Fried et. al 2002).

In this context it seems appropriate to question the suitability of the different models. There are some interesting earlier studies into this issue which compare the results obtained from applying some of the proposed models to a specific sample (Worthington and Dollery, 2002). In this study, in addition to considering new options, we concentrate on their advantages and disadvantages from both a methodological and practical perspective. Through this analysis our aim is to point out the main aspects of each technique that must be taken into account when it comes to deciding which option is the most appropriate to deal with this type of variables in an empirical study.

In order to illustrate this issue, we analyse a particular case. According to the characteristics of the data set and the preliminary results obtained in a standard DEA, an extension of the model proposed by Fried et. al (1999)is used in order to discount the effect of non-controllable inputs. This model has not been applied before to the measurement of efficiency in schools.

To this end, our article is organised as follows. Section 2 is a brief synopsis of some important issues concerning the measurement of efficiency in education and Data Envelopment Analysis (DEA). Section 3 presents and analyses the different options for incorporating nondiscretionary inputs into the measurement of efficiency. In section 4 , we analyse the performance of a group of Spanish high schools using DEA and present the main results obtained by applying the most appropiate approach (from a theorical and practical point of view) for these data in order to include non-discretionary inputs in the assessment. Section 5 shows the main conclusions. 


\section{THE MEASUREMENT OF EFFICIENCY IN THE EDUCATIONAL SECTOR}

Despite the great number of papers published in recent decades about the assessment of efficiency in education, the production function in the sector is still unknown (Engert, 1996). There are several explanations for this. Education is not an instantaneous thing but generates its effects in the medium term; the output, which is multi-dimensional and difficult to measure, is the consequence of a complex process influenced by many factors, some outside the control of the productive units. This makes it extraordinarily difficult to define a general educational production function that accurately includes all relevant aspects of the school production process and, consequently, making it possible to measure efficiency though a simple comparison between real results and those which could potentially be achieved (Hanushek, 1986).

The main interest of researchers in this area had been trying to define and measure the school output, identifying the factors that influence it most and linking the former with the latter while respecting the sector's special characteristics.

The measurement of educational output is usually restricted to those aspects that are relatively easy to measure and are directly related to the basic objectives of the relevant educational level. In the case of secondary education, it is usual to use the results achieved by students in an homogeneous test for all schools at the end of the school year.

With respect to inputs, despite the difficulties presented by the specification of an educational production function, there is empirical evidence to identify the factors that have a greater influence on school output. The Coleman Report (1966), which analysed the behaviour of a broad sample of non-university educational schools and is one of the most influential studies in the literature, concluded that the characteristics of pupils - a variable on which the centres in principle do not exercise any 
control - affected performance more than the typical resources of schools such as the number of teachers, class sizes or the school costs.

The publication of this report led to a wide-ranging debate between those who hold that these factors have no influence on educational results (Hanushek, 1986) and those who believe that spending more on education produces better results (Pritchett and Filmer, 1999). In any case, a study which aims to measure the productive efficiency of a group of schools must also consider these productive factors, since in the concept of technical efficiency is implicit the idea of how well resources are used.

The case of exogenous or environmental variables, which are common in other productive sectors, is different. Their influence on school output has been widely confirmed by empirical evidence and it is usually associated with a specific producer characteristic which may affect results (Pedraja and Salinas, 1996). Examples in the educational sector are the type of ownership of the schools (public or private) or their location (urban or rural). In these circumstances, the usual solution is to group units and compare them with those operating in a similar environment.

On the other hand, the representative variables of pupil characteristics, which are also sometimes considered as exogenous, are inputs which have a direct effect on the productive process and influence the results. These inputs, which the units cannot control (non-controllable inputs), should be considered in the efficiency evaluation so that those for which the educational centres are responsible can be calculated.

However, public data about these variables are not usually available, thus simple proxies for them are used in many studies ${ }^{1}$. One way to overcome these limitations, although costly and therefore infrequently used, is to conduct surveys of pupils in order to obtain

\footnotetext{
${ }^{1}$ Some examples are the studies by Bessent et. al (1982) or Thanassoulis and Dunstan (1994), which approximate the economic situation of families by using the percentage of pupils entitled to discounted meals.
} 
information on the factors identified in the literature as the most influential: the socio-economic and family environment, the innate ability of the students and the characteristics of their class mates (peer group effect).

With respect to the technique used to measure the relative efficiency of schools, two main alternatives can be considered: parametric and non-parametric methods ${ }^{2}$. In the literature, on the one hand, some studies comparing efficiency scores generated by both techniques for a specific sample (Bates, 1997; Chakraborty et. al, 2001; Mizala et. al, 2002) may be found. On the other, there are studies using Monte Carlo experiments where the underlying production technology is known ( $\mathrm{Yu}$, 1998). Nevertheless, most authors use non-parametric approximations and, specifically, Data Envelopment Analysis (DEA) ${ }^{3}$. This choice is based, amongst other reasons, on its great flexibility, which makes it particularly suitable in an area such as education where the production function is unknown, and on its ability to adapt to processes involving not only a range of inputs but also a series of intermediate outputs, rather than a single final input ${ }^{4}$. Moreover, in recent years different methods have been developed to incorporate in the technique the fact that there are noncontrollable inputs when efficiency scores are calculated, which is of particular interest in the educational sector.

DEA, introduced by Charnes, Cooper and Rhodes (1978), is characterised by the fact that it does not impose a specific functional form on the production function, but rather establishes certain assumptions about the properties of technology which allow the definition of the set of feasible productive processes whose frontier envelops the observed data. The standard formulation of the programme can take several forms according to different criteria, so it can be oriented to reduce input values

\footnotetext{
${ }^{2}$ See Lovell (1993) or Coelli et. al (1998) for a detailed discussion on the methods for analyzing technical efficiency.

${ }^{3}$ Charnes et. al (1981), Bessent et. al (1982), Smith and Mayston (1987), Thanassouliss and Dunstan (1994), Chalos (1997) or Thanassouliss and Portela (2002) are some examples.
} 
or increase output values. It can also be presented as a fractional programme (the original model), linear or dual. However, they all share the same approach: the efficiency of each unit depends on the ability of each producer to improve their results or reduce the consumption of resources while being subject to certain restrictions that reflect the activity of other producers.

From our perspective, if the aim is to evaluate the behaviour of a group of units, with a restricted budget, seeking to obtain the best possible results, it is advisable to use an output-orientated programme. In terms of its formulation, the dual programme is the most common option ${ }^{5}$ :

$$
\begin{array}{lll}
\text { Max } & \phi+\varepsilon \sum_{i=1}^{m} s_{i}^{-}+\sum_{r=1}^{s} s_{r}^{+} & \\
\text {s.a. } & \sum_{j=1}^{n} x_{i j} \lambda_{j}+s_{i}^{-}=x_{i 0} & i=1,2, \ldots, m \\
& \sum_{j=1}^{n} y_{r j} \lambda_{j}-s_{r}^{+}=\phi y_{r 0} & r=1,2, \ldots, ., S \\
& \lambda_{j} \geq 0 ; s_{r}^{+} \geq 0 ; s_{i}^{-} \geq 0 & \mathrm{j}=1,2, \ldots, \mathrm{n}
\end{array}
$$

where $\phi_{0}$ is the efficiency score, $\varepsilon$ is an infinitesimal non-Archimedean, $\lambda_{i}$ are the weightings and $s_{i}^{-}$and $s_{r}^{+}$are the inputs slacks and outputs slacks respectively. If the score is equals one the producer is relatively efficient compared to other units. If the score is lower than one, the unit evaluated is inefficient as the sample contains other units which perform better.

This formulation of the programme is particularly attractive since, in addition to allocating an efficiency score to each unit, it allows possible

\footnotetext{
${ }^{4}$ Seiford and Thrall (1990) consider that using DEA is preferable to any other type of analysis when the objective is to measure the efficiency of a group of organisations producing various outputs.

${ }^{5}$ The model defined corresponds with the original version of DEA proposed by Charnes, Cooper and Rodhes (1978), which assumes a productive technology characterised by an assumption of constant scale returns. This highly restrictive assumption was later relaxed
} 
additional reductions in inputs or potential increases in outputs to be detected in specific cases, using the slacks estimated for each variable. This interesting information is complementary to that offered by the efficiency score and may be extremely useful when it comes to identifying the source of possible producer inefficiencies.

\section{DIFFERENT OPTIONS FOR INCORPORATING NON- CONTROLLABLE INPUTS: ADVANTAGES AND DISADVANTAGES.}

A review of different options in the literature in order to incorporate exogenous factors in the assessment of efficiency allows us to make an initial distinction between methodologies using one and several stages. In one stage models, non-controllable inputs are included from the outset in the calculation of efficiencies using a DEA alone. Multi-stage models use a DEA to estimate efficiency scores in an initial evaluation without including non-discretionary inputs and then subsequently correct them to take account of the effects of such inputs. This correction can be applied directly to the scores or by modifying the original values of the variables, leading to new options within the second group.

From this perspective it seems sensible to seek a guide for selecting the most appropriate options. We will therefore examine the principal advantages and disadvantages of the options in the literature ${ }^{6}$ combining a theoretical perspective with a more practical view according to the objective of the analysis and the characteristics of the available data set.

\subsection{One stage models}

in the study by Banker, Charnes y Cooper (1984) with the introduction of a new restriction in the programme to allow variable scale returns: $\Sigma \lambda_{j}=1$.

6 This analysis sets aside other methods which try to explain possible producer inefficiencies by the influence of ambiental or environmental variables such as the models of Charnes et. al (1981), Pastor (1994) or Daraio et. al (2005). 
One stage models (Banker and Morey, 1986; Golany and Roll, 1993; and Ruggiero, 1998) are the most frequently used option ${ }^{7}$. These models modify the restrictions of the standard DEA programme by incorporating the uncontrollable nature of some of the inputs used. With this modification, if the model is oriented to minimise inputs the equiproportional reduction of the entire input vector is not pursued, but only the subvector formed by controllable inputs.

The principal advantage is its lack of complexity as it simplifies the calculation of efficiency scores by incorporating all the relevant variables in a single DEA. However, this option presents some methodological problems. The first of these is that it is limited to an input-oriented approach when, if we are trying to evaluate the performance of the schools, an output-oriented approach would be more recommendable. Moreover, with this approach all the inputs are fixed and it is not possible to treat those outside the schools' control in a differentiated manner. The second issue is that the efficient units are the same as those which would be obtained by using a DEA in which all inputs were controllable by the units. This happens because the frontier is the same in both cases and, consequently, only the scores of the inefficient units are modified. The third problem, which arises from the flexibility of the technique itself, is that as the number of variables increases (through the introduction of exogenous variables), the opportunities for a unit to become classified as efficient increase automatically (Nunamaker, 1985). These limitations lead us to examine the opportunities offered by multi-stage models.

\subsection{Multi-stage models}

Although these models have been criticised for not explicitly including the effects of exogenous factors in the first stage, the fact is that they do consider these effects implicitly in estimating efficiency scores.

\footnotetext{
${ }^{7}$ Most of computer programmes specifically developed for DEA allow non-controllable inputs to be included automatically using this option. For a review of DEA computer programmes in the market, see Barr (2004).
} 
The key is to calculate and discount correctly the effect of these factors to obtain final efficiency scores which reflect solely the performance of the units.

In this respect, two alternative methods may be identified: a direct adjustment of the initial efficiency scores themselves by using econometric techniques (second stage models), or an indirect adjustment by correcting variables (inputs/outputs), according to how they are affected by nondiscretionary inputs, and applying a new DEA to the adjusted values after that (adjusted value models).

\subsubsection{Second stage models}

These models, usually known in the literature as regression or second stage analyses, consider non-controllable inputs $\left(Z_{j}\right)$ as explanatory variables in a regression where the dependent variable is the initial efficiency score $\left(\theta_{j}\right)^{8}$. Once $\hat{\beta}_{j}$ are estimated, the initial scores are corrected according to the values of exogenous factors for each unit.

$$
\theta_{j}=f\left(Z_{j}, \beta_{j}\right)+u_{j}
$$

This adjustment can be made directly through the predicted values (McCarty and Yaisawarng, 1993) or following the technique proposed by Greene (1980) to avoid any unit having a lower estimated score after the correction (Noulas and Ketkar, 1998) ${ }^{9}$.

Its main advantage compared to other multi-stage models is its simplicity as the adjustments are performed directly on the efficiency scores obtained in the first stage. Nevertheless, this fact introduces a first limitation as the correction only takes into account the radial component of

\footnotetext{
${ }^{8}$ While some studies use ordinary least squares (Ray, 1991), others use a Tobit (Kirjavainen and Loikkanen, 1998) because the efficiency scores are censored.

This mechanism consist of adding the largest positive residual from all the residuals to the predicted value to get the adjusted efficiency.
} 
inefficiency and not the possible inefficiencies derived from the existence of slacks.

Another limitation of a practical nature is that it can only be applied if there is a significant relationship between the efficiency scores and exogenous variables. Many studies assume, erroneously, that if the output depends on uncontrollable outputs, there must be a significant relationship between these factors and the efficiency score. However, this assumption does not generally turn out to be correct, as efficiency depends on several factors. As a consequence, the use of this model is conditional upon there being a significant relationship between both variables.

A fundamental criticism of these models is that standard approaches to statistical inference in the context of limited dependent variable models are invalid. This is due to the existence of correlation among efficiency scores estimated in the first stage, since they are estimated from data of all the units making up the sample (Xue and Parker, 1999). However, this problem can be overcome by using bootstrap techniques (Simar and Wilson, 2003) ${ }^{10}$. In particular, these authors have developed two procedures (algorithms) for the second stage of production efficiency analysis that allow for valid statistical inference ${ }^{11}$. In fact, some of the most recent papers in the education field apply these techniques to include non-discretionary inputs in the measurement of technical efficiency of units ${ }^{12}$.

These proposals are very attractive if the objective is to find whether the sign is positive or negative and how much effect exogenous factors have on efficiency indicators. However, we should remember that with adjustments made using this option, scores higher than one (or lower with an input orientation) may be obtained for all the units comprising the

\footnotetext{
10 The idea of applying bootstrapping techniques in measuring efficiency was already suggested by Simar and Wilson (1998) and also applied by González and Miles (2002) for two Spanish public services.

${ }^{11}$ The analytical expression of these algorithms are set out in Simar and Wilson (2003).
} 
sample $^{13}$. This fact, which is explained by the zero sum criterion used in the estimation of regressions, makes it impossible to construct a production frontier and, consequently, difficult to establish production objectives for the units from the set of reference (efficient) units.

\subsubsection{Adjusted value models}

In addition to regression or second stage models, the literature offers other more complicated multi-stage applications, based on using the total slacks (radial and non-radial components) obtained in the first stage. The objective of these models is to identify the part of the slacks which is explained by the effect of non-discretionary inputs and the part associated with producers' own technical inefficiency. This decomposition means that adjustments can be made to the values of variables (controllable inputs and outputs) allowing the effect of exogenous factors to be discounted. The last stage, which is the same in all models, consists in running a new DEA incorporating the corrected values of variables according to noncontrollable inputs attributed to each unit. The new estimated scores establish exclusively the efficiency level at which each producer operates.

Within these models, the available options are differentiated by the technique employed in breaking down the different factors that comprise the slacks. The three stage model (Fried and Lovell, 1996) chooses a DEA, the four stage model (Fried et. al, 1999) uses censured regressions and the model proposed by Fried et. al (2002) opts for stochastic frontier regressions.

a) Three stage model with DEA (Fried and Lovell, 1996)

The mechanism used for the discomposition of different factors is a DEA which incorporates slacks as controllable inputs and non-controllable

${ }^{12}$ Oliveira and Santos (2005) use the first algorithm while Afonso and St. Aubyn (2005) applies the second one to correct the scores obtained in first stage. 
inputs as outputs. This introduces a problem of minimising inputs (slacks) subject to the value of the outputs (non-controllable inputs). In other words, the aim is to determine the extent to which the former can be reduced while taking the value of the latter to be fixed.

$$
\begin{array}{ll}
\min & \beta_{0} \\
\text { s.a. } & \sum_{i=1}^{I} \lambda_{i} x_{f i}-s^{-{ }^{-}}=x_{f 0} \\
& \sum_{i=1}^{I} \lambda_{i}\left[\left(1-\theta_{0}\right) x_{d}+s_{d}^{+}\right]_{i}+s^{+^{+}}=\beta_{0}\left[\left(1-\theta_{0}\right) x_{d}+s_{d}^{+}\right]_{0} \\
& \sum_{i=1}^{I} \lambda_{i}=1 \\
& \lambda_{i}, s_{d}^{+^{-}}, s^{-^{-}} \geq 0
\end{array}
$$

where the total slack detected in the first stage for each producer in the variable $x_{d}$ is given by the expression: $\left[\left(1-\theta_{0}\right) x_{d}+s_{d}^{+}\right]_{i}$. As a result of this process the attainable target is obtained for each unit, taking account of how many non-discretionary inputs it has. These targets make it possible to identify what part of the slacks is explained by the influence of external effects, $\quad \beta_{0}\left[\left(1-\theta_{0}\right) x_{d}+s_{d}^{+}\right]_{i}$, and what is due to inefficiency, (1$\left.\beta_{0}\right)\left[\left(1-\theta_{0}\right) x_{d}+s_{d}^{+}\right]_{i}$. The values of inputs and outputs can be corrected following the original model or the alternative option proposed by Muñiz (2002).

Its principal advantage is the use of non-parametrical techniques in all stages of the analysis, which is very useful not only where there is ignorance about the productive process in sectors such as education, but also to overcome problems of bias that characterise the estimation of regressions using econometric techniques.

\footnotetext{
${ }^{13}$ This suspect is verified in the evaluation of the study educational results of a group of countries carried out by Afonso and St. Aubyn (2005).
} 
Its main weakness is the impossibility of applying a downwards correction for units classed as efficient in the initial estimation. This appears inappropriate if these units have a relatively high level of noncontrollable inputs, which involves a practical requirement when it comes to selecting the technique used in the process related to the characteristics of the available data set ${ }^{14}$.

b) Four stage model (Fried et. al, 1999)

To distinguish the different effects incorporated in slacks, this model uses a system of equations formed by $n$ Tobit regressions, one for each variable. The dependent variables are the total slacks of each output obtained in the initial DEA and the regressors are the exogenous factors:

$$
I T S_{j}^{k}=f\left(Z_{j}^{k}, \beta_{j}, u_{j}^{k}\right)
$$

where $I T S_{j}^{k}$ represents total slacks obtained in the first stage, $Z_{j}^{k}$ is a vector representing non-controllable inputs, $\beta_{j}$ is a vector of coefficients and $u_{j}^{k}$ is the error term.

From an applied perspective, its output-oriented approach is especially appropriate for including the effect of non-discretionary inputs in the educational sector as this technique only corrects output values -the only variables influenced by these factors-. It can also correct the scores of units considered efficient in the first stage if these have high values of exogenous factors.

The similarity of this method with second stage models means that it shares certain of their limitations. One is of a practical kind, such as the fact that there has to be a significant relationship between the slacks and exogenous variables so that it can be used and another, which is more

\footnotetext{
${ }^{14}$ This is a decisive factor in the decision of its promoters to abandon it, as described in
} 
important, of a methodological nature to do with problems of bias in the estimation of regressions ${ }^{15}$. While the former difficulty affects the possibility of applying it to certain samples, the latter can be overcome by using bootstrap technique when estimating the equations system of the original regressions, though this is an option undeveloped in the literature.

c) Three stage model with stochastic frontier (Fried, Lovell, Schmidt and Yaisawarng, 2002)

The model's starting point is that the total slacks obtained in the first stage have three sources: producer inefficiency, the influence of exogenous factors and random noise. To separate these three components, a stochastic frontier is estimated in the second stage with the slacks as dependent variable, the non-controllable inputs as independent variables and a composed error term which differentiates between the effects of inefficiency and statistical noise. The stochastic frontier regression takes the following functional form:

$$
s_{n i}=f^{n}\left(z_{i} ; \beta^{n}\right)+v_{n i}+u_{n i} \quad n=1, \ldots, N \quad i=1, \ldots ., I
$$

where $s_{n i}=x_{n i}-X_{n} \lambda \geq 0$ are the total slacks of the outputs (inputs), $f^{n}\left(z_{i} ; \beta^{n}\right)$ are the deterministic frontiers of feasible slacks, $z_{i}=\left[z_{i 1}, \ldots \ldots z_{k i}\right]$, are the variables of exogenous factors, $\beta^{n}$ are the vectors of the parameters to be estimated and, finally, $v_{n i}+u_{n i}$ represent the errors, with the first component representing random noise $\left[v_{n i} \approx N\left(0, \sigma_{v n}^{2}\right)\right]$ and the second $\left(u_{n i} \geq 0\right)$ representing technical inefficiency. These regressions can be estimated through maximum likelihood, if some assumptions are made.

\footnotetext{
Fried et. al (2002).

${ }^{15}$ The slacks can also be calculated using the information of the units making up the sample, with the requirement for independence of errors not being fulfilled.
} 
The stochastic nature of the proposed method allows the incorporation in the analysis of the effect of factors not included in it (random noise). This option also corrects the scores of those units considered as efficient in first stage in the case that they have favourable exogenous resources. Finally, it is also useful in identifying possible extreme values or outliers.

With respect to the disadvantages, we may note the excessively favourable criterion it uses to adjust the initial efficiency scores (worse placed unit in all dimensions), which produces final scores remote from the real production possibilities, as well as problems of bias in the estimations given the shortage of independence amongst the composed errors.

\subsection{Criteria to select the most appropiate model}

As can be seen, an analysis of the different options does not allow us to conclude that any one is better than the others, that is, none of them is free of constraint. Thus, the choice amongst them will depend on the characteristics of the available data set, the fulfillment of some requirements and the specific objectives of the study. However, the analysis allow us to draw some conclusions.

First of all, we think that a multi-stage approach is much more suitable than the single-stage option when including non-controllable inputs in efficiency analysis because of different reasons. The most important limitation of the latter option is that its results depend on the number of variables included.

Within multi-stage models, the most recent developments have shown that results obtained with classic second-stage models are invalid. So when the main objective of the study is to identify the relevance (and the sign) of the effect of non-discretionary inputs on efficiency scores, the 
approach proposed by Simar and Wilson (2003) will be the most appropriate $^{16}$.

Although second-stage models can be very useful to identify the effect of exogenous variables on efficiency, this approach loses some of the information derived from the initial DEA assessment (the non-radial components of inefficiency) and does not allow us to construct new efficiency scores without an upward bias (or downward with an input orientation). Therefore, we think that adjusted value models are the most appropriate approach to deal with non-discretionary inputs if the aim of the study is to obtain new scores in which their effect is included.

Amongst the three alternative proposals considered we prefer the four-stage model rather than the others, provided that bootstrap techniques are applied in the estimation of Tobit regressions to avoid bias. This selection is based on two facts; i) its ability to adjust upward and downward the initial scores without bias; and ii) the regression is the most appropriate mechanism to separate the effect of non-discretionary inputs from the inefficiency in slacks. However, this method can only be used if there is a significant relationship between the initial scores and exogenous variables. Otherwise, the three stage model would be the most appropriate option since the use of DEA in all the stages does not require the existence of such relationship between variables. Nonetheless it must be considered that this approach can lead to an overestimation in the final scores especially for those units with a relatively high level of noncontrollable inputs. Finally, although the three stage stochastic model is very useful for detecting the effect of other factors not included in the analysis (random noise), this proposal is not very appropriate because it sets non-real targets for the units (too easy to achieve) and also requires improvements - not yet developed in the literature- to eliminate estimation biases.

${ }^{16}$ The choice between the algorithm one and two depends on the sample size. 


\section{EMPIRICAL APPLICATION}

In this section we estimate the level of technical efficiency in a group of Spanish high schools in the Extremadura region. The sample comprises eighty public schools in the region for which we have a great deal of information for the 2001-2002 school year on the non-discretionary inputs (obtained from student surveys), the results achieved by pupils in a standard test and the schools' productive factors.

This information is used to estimate the efficiency scores of the schools without including the information about their non-controllable inputs. Subsequently, once the results have been analysed and taking into account the characteristics of the sample, we select an appropriate model to discount the effect of non-controllable inputs and obtain a new estimation of the schools' efficiency.

\subsection{Variables}

The results achieved by pupils in the University Entrance Exam are used as an output. All students who wish to go to a Spanish University (public or private institutions) must make this commom exam on completing their secondary education. Two variables have been constructed using this information. The average mark of pupils passing the exam (MARKS), as an indicator of a qualitative nature, and the percentage of pupils who pass the exam compared to those enrolling in a university course (ACCEPTED).

As controllable inputs, the two variables most often used in the literature as being representative of the factors managed by the schools are chosen ${ }^{17}$. The total number of teachers in the school per 100 pupils

\footnotetext{
${ }^{17}$ Bessent et. al (1982), Smith and Mayston (1987), McCarty and Yaisawarng (1993) or Muñiz (2002) amongst others.
} 
(TEACHERS) and the total current cost per student excluding school personnel costs during the year (COSTS $)^{18}$.

The usual difficulty of an absence of available information on the non-controllable inputs has been overcome in our study through a survey of the pupils of all the schools evaluated. These gave twenty-two variables offering information on a large variety of circumstances which may affect pupils' academic performance. However, all of them are not included in the analysis since some are not statistically related to the representative variables of the output and others provide redundant information. Thus, departing from the current bibliography and statistics criteria, eleven variables associated to the most influential factors on academic achievement are selected. Such factors are the socio-economic and family environment of students, their own abilities or the influence of class mates (peer group effect) ${ }^{19}$. The variables, defined as the percentage of pupils who fulfil certain requirements, are listed in Table 1 in the Annex.

In any case, given the number of variables, which is still high, and the fact that none of them represents the factors addressed in the literature and mentioned above particularly accurately, we decided to use Principal Component Analysis $(\mathrm{PCA})^{20}$. This technique makes it possible to summarise all the information available in a lower number of variables with minimum loss of information. These are the variables which will finally

\footnotetext{
${ }^{18}$ We should point out that, taking into account the type of variables used, the concept of efficiency to be measured is not strictly technical efficiency as one input (costs other than personnel) is expressed in monetary terms, but they are very close to it. However, this cannot be considered as allocative efficiency as we do not include the price of inputs which are clearly unknown in this field.

${ }^{19}$ In the analysis only variables with a clear influence on two measures of output have been included. Ten non-significant variables in the explanation of any one of the output variables have been discarded. Table 2 and 3 show that only 12 variables account for the percentage of students accepted, while 16 are significantly related to the variable MARKS. The variable "GRANT" (percentage of students with a public grant) has been removed because it is significantly correlated to all variables, as can be seen in Table 4 in the Annex (this table shows the Pearson coefficient amongst the 12 significant variables).

${ }^{20}$ Smith and Mayston (1987) were the first to recommend the use of this technique in order to reduce the number of non-discretional factors in the evaluation of the efficiency of schools.
} 
be incorporated in the assessment of efficiency as representative variables of so-called non-controllable inputs.

PCA allows us to identify three components which cover $78 \%$ of the original information (see Annex, Table 5). Next, looking at the rotated component matrix, we can verify which variables are associated with each of the variables. Table 6 in the Annex shows that the first factor is comprised of five variables concerning family incomes, level of education and profession of the fathers (in other words, those determining the student's socio-economic environment). The second is comprised of four variables representing pupils' ability, meaning variables related to their academic record and the opinion that parents have about their academic potential. Finally, the third factor is made up of two variables which offer us information about the characteristics of class mates or peer group effect such as those relating to the pupils' aspirations or their efforts to keep their studies up to date.

In summary, for the empirical application we used two variables for school output (MARKS and ACCEPTED), two offering information about inputs controlled by the schools (TEACHERS and COSTS) and three representing non-discretionary inputs (the three components obtained from the eleven variables described above). Table 1 lists the principal statistichs for these variables.

Table 1: Statistical information about the variables

\begin{tabular}{||c|c|c|c|c||}
\hline & MINIMMI IMM & MM XIMMI IMM & DVFR ASF & ST MNI ARn nFV \\
\hline MARKS & 50.28 & 72.52 & 59.59 & 4.0987 \\
\hline ACCEPTED & 12.50 & 86.42 & 40.33 & 14.0819 \\
\hline TEACHERS & 7.68 & 13.21 & 9.64 & 1.1490 \\
\hline COSTS & 65.63 & 543.86 & 161.19 & 66.8621 \\
\hline COMP 1 & 0.00 & 4.60 & 1.3050 & 1.0000 \\
\hline COMP 2 & 0.00 & 5.06 & 2.6922 & 0.9993 \\
\hline COMP 3 & 0.00 & 5.27 & 1.8900 & 1.0000 \\
\hline
\end{tabular}




\subsection{Results obtained with a standard DEA analysis}

In this section we assess the schools' efficiency by applying a standard $\mathrm{DEA}_{2}$ i.e. using only discretional inputs. As explained earlier, the approach is to maximise outputs and we consider variable returns to scale both to eliminate possible inefficiencies to do with the size of the schools and because it is the correct option in cases where ratios are used in inputs or in outputs (Hollingsworth and Smith, 2003).

The results in Table 7 in the Annex show eight efficient units (HS $12,18,24,31,44,52,56$ and 71 ), which can in turn be divided into two groups. The first (HS 12, 31, 56 and 71) comprises units which have achieved the best results in the University Entrance Exam, and the second (HS 18, 24, 44 and 52) represents those with lower input values. With regards to the inefficient units, those with the lowest scores are those with the worst results in the University Entrance Exam (HS 10, 37, 53 or 64), or those which, in spite of having greater resources, achieved mediocre results (HS 15, 48 or 62).

This initial assessment would be correct if all the schools had pupils with similar characteristics, which is not true in the light of the information contained in Table 1. Therefore it is necessary to include these variables in the evaluation process.

First of all we must test whether our exogenous variables have any influence on initial efficiency scores or not. For that propose we use the second-stage approach with a truncated regression:

$$
\text { Scores }=\beta_{0}+\beta_{1} C O M P 1+\beta_{2} C O M P 2+\beta_{3} C O M P 3+u_{i}
$$

As can be seen in Table 2, the results of the Tobit estimation show that all variables are significantly related to scores. However, those results are invalid, as explained above. In order to avoid the bias, we have 
applied the single bootstrapping method proposed by Simar and Wilson $(2003)^{21}$, through which we have confirmed that result, that is, all the variables are significant.

The next step is to obtain new efficiency scores which include the effect of non-discretionary inputs. In principle, we could opt to use this approach, but the scores obtained would not allow us to identify any efficient unit (See Table 7 in Annex) and, consequently, we would not be able to set production and consumption targets for each unit.

Table 2: Results of the Tobit regressions with scores

\begin{tabular}{||c|c|c||}
\hline & McC\&Y (1993) & SW (2003) \\
\hline & Tobit Regression & Tobit with bootstrap \\
\hline Dependent Variable & DEA Scores & DEA Scores \\
\hline Constant & $1.2985^{\star \star}$ & $1,3162^{\star \star}$ \\
& $(0,0238)$ & $(0,0247)$ \\
\hline \multirow{2}{*}{ CP1 } & $-0.0378^{\star \star}$ & $-0,0473^{\star \star}$ \\
& $(0,0064)$ & $(0,0079)$ \\
\hline CP2 & $-0.0235^{\star *}$ & $-0,0263^{\star \star}$ \\
& $(0,0064)$ & $(0,0071)$ \\
\hline \multirow{2}{*}{ CP3 } & $-0.0187^{\star *}$ & $-0,0205^{\star \star}$ \\
& $(0,0064)$ & $(0,0069)$ \\
\hline
\end{tabular}

Note: The standard errors of the estimated parameters are shown in brackets.

The subscores ${ }^{* *}$ indicate that the parameter estimated is significant at 5 per cent level.

Therefore, since our aim is to obtain scores which discriminate between efficient and inefficient units, we should use an adjusted value model. Furthermore, these models use the total slacks (radial and nonradial components) obtained in the first stage, and all available information from initial DEA is considered.

Amongst different alternatives following this approach we prefer the four stage model (using bootstrap to estimate regressions) rather than other ones, our selection being based on the reasons in Section 3.3. Nevertheless, to apply this model there must be a significant relationship

\footnotetext{
${ }^{21}$ We have used the single bootstrapping (Algorithm 1) proposed by those authors because it perfoms better than Algorithm 2 when the sample is small (80 units).
} 
between non-discretionary inputs and the slacks obtained in the first stage. The results in Table 2 confirm this relationship for all variables ( $p$ values for the three components are very close to 0 ) both in the estimation of the initial Tobit regressions and the estimation performed using a 10,000 iteration bootstrap process. Therefore, an extended four-stage model has been used to estimate the efficiency of schools with the parameters obtained by the bootstrapping method to adjust the values of outputs in order to include the effect of non-controllable inputs.

Table 3: Results of the Tobit regressions with slacks

\begin{tabular}{|c|c|c|c|c|}
\hline \multirow[b]{2}{*}{$\begin{array}{l}\text { Dependent } \\
\text { Variable }\end{array}$} & \multicolumn{4}{|c|}{ Independent Variable } \\
\hline & $\begin{array}{l}\text { Slacks } \\
\text { Accepted }\end{array}$ & Slacks Marks & $\begin{array}{c}\text { Slacks } \\
\text { Accepted with } \\
\text { Bootstrap }\end{array}$ & $\begin{array}{c}\text { Slacks } \\
\text { Marks with } \\
\text { Bootstrap }\end{array}$ \\
\hline Constant & $\begin{array}{c}30.9050^{\star *} \\
(2.6931)\end{array}$ & $\begin{array}{c}21.6691^{* *} \\
(1.7208)\end{array}$ & $\begin{array}{c}30.9112^{\star \star} \\
(2.6790)\end{array}$ & $\begin{array}{c}21.6763^{\star \star} \\
(1.7084)\end{array}$ \\
\hline CP1 & $\begin{array}{c}-3.1547^{\star \star} \\
(0.7406)\end{array}$ & $\begin{array}{c}-2.7603^{\star \star} \\
(0.4732)\end{array}$ & $\begin{array}{c}-3.1539^{\star \star} \\
(0.7402)\end{array}$ & $\begin{array}{l}-2.7671^{\star *} \\
(0.4748)\end{array}$ \\
\hline CP2 & $\begin{array}{c}-3.8893^{\star \star} \\
(0.7416)\end{array}$ & $\begin{array}{c}-1.7736^{\star *} \\
(0.4739) \\
\end{array}$ & $\begin{array}{l}-3.8794^{\star \star} \\
(0.7401)\end{array}$ & $\begin{array}{c}-1.7690^{\star \star} \\
(0.4712)\end{array}$ \\
\hline CP3 & $\begin{array}{l}-2.1842^{\star *} \\
(0.7411) \\
\end{array}$ & $\begin{array}{c}-1.3464^{\star *} \\
(0.4735) \\
\end{array}$ & $\begin{array}{c}-2.1956^{\star *} \\
(0.7375) \\
\end{array}$ & $\begin{array}{c}-1.3497^{\star *} \\
(0.4733) \\
\end{array}$ \\
\hline
\end{tabular}

Note: The standard errors of the estimated parameters are shown in brackets. The subscores ${ }^{* *}$ indicate that the parameter estimated is significant at 5 per cent level.

\subsection{Results from incorporating the effect of non-discretionary inputs}

Comparing the scores obtained from the four stage model with the initial scores (Table 4) allows us to draw some conclusions. Firstly, there is an increase in average efficiency. More units benefit from the inclusion of non-discretional inputs than those which are negatively affected and the efficiency gains outstrip the losses (see Annex, Table 7).

Secondly, the number of efficient units increases to twelve, as a consequence of five becoming efficient (HS 22, 25, 34, 42 and 78), and one (HS 24) no longer being efficient. The new efficient centres have been benefited in the second estimation because the scores assigned to each 
unit are constructed taking into account additional resources, thus implying that all the units are evaluated according to their true productive potential.

As with the units which become efficient, there are others, which though they do not reach the frontier, clearly move closer to it. This is the case with the schools like HS 28, 33 ó 36 . All were negatively affected in the first evaluation which ignored the type of pupils in each school. However, by applying the four stage methodology, all reduce their score and are amongst the ten best inefficient units.

Table 4: Differences between the initial DEA and the extended four-stage model

\begin{tabular}{||c|c|c|c|c||}
\hline & Efficient units & $\begin{array}{c}\text { Average } \\
\text { efficiency }\end{array}$ & $\begin{array}{c}\text { Percentage of } \\
\text { units with a } \\
\text { difference }>5 \%\end{array}$ & $\begin{array}{c}\text { Spearman's } \\
\text { coefficient }\end{array}$ \\
\hline Initial DEA & 8 & 1,1504 & 57.5 & 0.714 \\
\hline $\begin{array}{c}\text { Modified 4 } \\
\text { stage }\end{array}$ & 12 & 1,108 & & \\
\hline
\end{tabular}

In the case of the unit that goes from being efficient to inefficient the opposite applies. The first DEA, in which not all the resources are taken into account, benefits this school as it is one of those which have better quality students. However, it can be seen in the subsequent evaluation that the school was not in fact maximising its results given its set of noncontrollable factors (Table 8 in the Annex).

Many others also obtain a score which is appreciably higher following the correction made using the four stage model, causing significant changes in the final classification of schools. The most noticeable are those affecting units 20,50 and 59 which are noteworthy for having a set of non-discretionary inputs which are clearly higher than the others. 
Finally, although the corrections to values are not too significant, a considerable number of units modify their scores. More than half change their score by more than $5 \%$ (Table 3 ). This changes the final ranking of the units as can be seen by the value of the Spearman coefficient range (0.714).

\section{CONCLUSIONS}

This study offers a detailed analysis of the advantages and disadvantages of different options proposed in the literature for incorporating the effect of non-controllable inputs when estimating efficiency scores. Their inclusion is essential in areas like education where output depends to a large extent on factors, such as socio-economic characteristics of the students and their families, which are outside of the schools' control.

Once certain options which are unsuitable from a methodological perspective have been discarded, it is impossible to say that one model is better than the rest in overall terms. Therefore, the choice will be affected by the specific objectives of the study and the characteristics of the available sample.

These conclusions were followed in estimating the efficiency of a group of Spanish high schools, applying a four stage model proposed by Fried et. al (1999) and adding a bootstrap to avoid problems of bias in the estimations. This approach, which had not been used in the field of education until now, can be considered as a very suitable option to identify the efficient units once the non-discretionary inputs have been included in the analysis. 


\section{REFERENCES}

AFONSO, A. and ST. AUBYN, M. (2005): "Cross-country Efficiency of Secondary Education Provision: a Semi-parametric Analysis with Non-discretionary Inputs", Department of Economics, Institute for Economics and Business Administration (ISEG), Technical University of Lisbon.

BANKER R.D.; CHARNES, A. and COOPER, W.W. (1984): "Some models for estimating technical and scale inefficiencies in Data Envelopment Analysis", Management Science, vol. 30, ㄲo 9, pp. 1078-1092.

BANKER, R.D. and MOREY, R.C. (1986): "Efficiency Analysis for exogenously fixed inputs and outputs", Operations Research, vol. 34, no 4, pp. 513-521.

BARR, R. (2004): "DEA Software Tools and Technology: A State-of-theArt Survey", in Cooper, W., Seiford, L. y Zhu, J.: "Handbook on Data Envelopment Analysis", Kluwer Academic Publishers.

BARRO, R. (2001): "Human Capital and Growth", American Economic Review, 91 (2), pp. 12-17.

BATES, J. (1997): "Measuring predetermined socioeconomic inputs when assessing the efficiency of educational outputs", Applied Economics, 29, pp. 85-93.

BESSENT, A.M., BESSENT, E.W., KENNINGTON, J. and REAGAN, B. (1982): "An application of mathematical programming to assess productivity in the Houston independent school district", Management Science, 28 (12), pp. 1355-1367.

CHAKRABORTY, K., BISWAS, B. and LEWIS, W.C. (2001): "Measurement of technical efficiency in public education: a stochastic and non-stochastic production function approach", Southern Economic Journal, 67 (4), pp. 889-905.

CHALOS, P. (1997): "An examination of budgetary inefficiency in education using data envelopment analysis", Financial Accountability and Management, 13, pp. 55-69.

CHARNES, A.; COOPER, W.W. and RHODES, E. (1978): "Measuring the efficiency of Decision Making Units", European Journal of Operational Research, vol. 2, ํㅡ 6, pp. 429-444.

CHARNES, A., COOPER, W.W. and RHODES, E. (1981): "Evaluating program and managerial efficiency: An application of Data Envelopment Analysis to Program Follow Through", Management Science, 27 (6), pp. 668-697. 
COELLI, T., RAO, D.S.P. and BATTESE, G. (1998): "An introduction to efficiency and productivity analysis", Kluwer Academic Publishers.

COLEMAN, J.S. et. al (1966): "Equality of Education Opportunity", Washington, DC; US. GPO.

DARAIO, C. and L. SIMAR (2005): "Introducing environmental variables in nonparametric frontier models: a probabilistic approach", Journal of Productivity Analysis, vol. 24, 1, pp. 93-121.

ENGERT, F. (1996): "The reporting of school district efficiency: the adequacy of ratio measures", Public Budgeting and Financial Management, 8, pp. 247-271.

FRIED, H.O. and LOVELL, C.A.K. (1996): "Searching for the zeds", paper presented at II. Georgia Productivity Workshop.

FRIED, H., SCHMIDT, S. and YAISAWARNG, S. (1999): "Incorporating the operating environment into a nonparametric measure of technical efficiency", Journal of Productivity Analysis, 12, pp. 249267.

FRIED, H., LOVELL, C.A.K., SCHMIDT, S. and YAISAWARNG, S. (2002): "Accounting for Environmental Effects and Statistical Noise in Data Envelopment Analysis", Journal of Productivity Analysis, 17(1/2), pp. 157-174.

GOLANY, B. and ROLL, Y. (1993): "Some Extensions of Techniques to Handle Non-Discretionary Factors in Data Envelopment Analysis", The Journal of Productivity Analysis 4, pp. 419-432.

GONZÁLEZ, X.M. and MILES, D. (2002): "Statistical precision of DEA: a bootstrap application to Spanish public services", Applied Economic Letters, 9, pp. 127-132.

GREENE, W. (1980): "Maximum Likelihood Estimation of Econometric Frontier Functions", Journal of Econometrics, 13, pp. 26-57.

HANUSHEK, E.A. (1986): "The economics of schooling: production and efficiency in public schools", Journal of Economic Literature, 24 (September), pp. 1141-1177.

HANUSHEK, E. and KIMKO, D. (2000): "Schooling, labor force quality, and economic growth", American Economic Review, 90 (5), pp. 1184-1208.

HOLLINGSWORTH, B. and SMITH, P. (2003): "Use of ratios in Data Envelopment Analysis", Applied Economics Letters, vol. 10, pp. 733-735. 
KIRJAVAINEN, T. and LOIKKANEN, H.A. (1998): "Efficiency differences of finnish senior secondary schools: an application of DEA and Tobit analysis", Economics of Education Review, vol. 17 (4), pp. 377-394.

LOVELL, C.A.K. (1993): "Production frontiers and productive efficiency" in FRIED, H., LOVELL, C.A.K. y SCHMIDT, S. (ed.): "The Measurement of Productive Efficiency: Techniques and Applications", Oxford University Press, New York.

McCARTY, T. and YAISAWARNG, S (1993): "Technical efficiency in New Jersey School districts", in FRIED, H., LOVELL, C.A.K. y SCHMIDT, S. (ed.): "The Measurement of Productive Efficiency: Techniques and Applications", Oxford University Press, New York.

MIZALA, A., ROMANGUERA, P. and FARREN, D. (2002): "The technical efficiency of schools in Chile", Applied Economics, 30, pp. 10891100.

MUÑIZ, M. (2002): "Separating Managerial Inefficiency and External Conditions in Data", European Journal of Operational Research, vol. 143-3, pp. 625-643.

NOULAS A. y KETKAR, K. (1998): "Efficient utilization of resources in public shools: a case study of New Jersey", Applied Economics, 30, pp. 1299-1306.

NUNAMAKER, T.R. (1985): "Using data envelopment analysis to measure the efficiency of non-profit organizations: A critical evaluation", Managerial and Decision Economics, vol. 6, no 1, pp. 50-58.

OLIVEIRA, M.A. and SANTOS, C. (2005): "Assessing school efficiency in Portugal using FDH and bootstrapping", Applied Economics, 37, pp. 957-968.

PASTOR, J. (1994): "How to discount environmental effects in DEA: An application to bank branches", Documento de Trabajo del Instituto Valenciano de Investigaciones Económicas.

PEDRAJA, F. and SALINAS, J. (1996): "An assessment of the efficiency of Spanish courts using DEA", Applied Economics, vol. 28, no 11, pp. 1391-1403.

PRITCHETT, L. and FILMER, D. (1999): "What education production functions really show: a positive theory of education expenditures", Economic of Education Review 18, pp. 223-239.

RAY, S.C. (1991): "Resource use efficiency in public schools: A study of Connecticut data", Management Science, vol. 37, no 12, págs. 1.620-1.628. 
RUGGIERO, J. (1998): "Non-discretionary inputs in data envelopment analysis", European Journal of Operational Research, 111, pp. 461469.

SEIFORD, L.M. and THRALL, R.M. (1990): "Recent developments in DEA: The matematical programming approach to frontier analysis", Journal of Econometrics, 46 (1/2), pp. 7-38.

SIMAR, L. and WILSON, P.W. (1998): "Sensitivity analysis of efficiency scores: how to bootstrap in nonparametric frontier models", Management Science, 44, pp. 49-61.

SIMAR, L. and P. W. WILSON (2003): "Estimation and inference in twostage, semiparametric models of production processes", Discussion Paper 0307, Institut de Statistique, Université Catholique de Louvain.

SMITH, P. and MAYSTON, D. (1987): "Measuring efficiency in the public sector", OMEGA International Journal of Management Science, $\mathrm{n}^{\circ}$ 15, pp. 181-189.

THANASSOULIS, E. and DUNSTAN, P. (1994): "Guiding Schools to Improved Performance Using Data Envelopment Analysis: An illustration with Data from a Local Education Autority", Journal of the Operational Research Society, vol. 45, no11, pp 1247-1262.

THANASSOULIS, E. y SILVA-PORTELA, M.C. (2002): "School outcomes: Sharing the responsability between pupil and school", Education Economics, 10 (2), pp. 183-207.

WORTHINGTON, A.C. and DOLLERY, B.E. (2002): "Incorporating contextual information in public sector efficiency analyses: A comparative study of NSW local government", Applied Economics, 34 (4), pp. 453-464..

XUE, M. and HARKER, P.T. (1999): "Overcoming the Inherent Dependency of DEA Efficiency Scores: A Bootstrap Approach", Working Paper, Wharton Financial Institutions Center, University of Pennsylvania.

YU, C. (1998): "The effects of exogenous variables in efficiency measurement: A Monte Carlo study", European Journal of Operational Research, 105, pp. 569-580. 


\section{ANNEX}

Table 1: Definition of the representative variables of non-discretionary inputs

\begin{tabular}{|c|l||}
\hline Name of variable & \multicolumn{1}{c|}{ Definition } \\
\hline PASSALL & Pupils who passed all their subjects last year \\
\hline NOREPEAT & Pupils who have never repeated a year \\
\hline ROCORD & $\begin{array}{l}\text { Pupils who passed all subjects between June and } \\
\text { September last year with high marks }\end{array}$ \\
\hline ASPIRATION & Pupils who studied for more than 10 hours a week \\
\hline PARENTSCONFIDENCE & Pupils wishing to study at university \\
\hline INCOMES & success \\
\hline FATHEREDUC & Pupils whose parents have high incomes \\
\hline MOTHEREDUC & Pupils whose father has a university education \\
\hline FATHERJOB & Pupils whose mother has a university education \\
\hline MOTHERJOB & Pupils whose father is a qualified professional \\
\hline \hline
\end{tabular}

Table 2. Individual regressions with "ACCEPTED” as dependent variable

\begin{tabular}{||c|c|c|c||}
\hline & COEFFICIENT & T-STATISTIC & PROB. \\
\hline SEX & 0,1531 & 1,3599 & 0,1775 \\
\hline PASSALL & $\mathbf{0 , 2 1 7 8}$ & $\mathbf{2 , 8 7 9 5}$ & $\mathbf{0 , 0 0 5 1}$ \\
\hline RECORD & $\mathbf{0 , 1 7 2 9}$ & $\mathbf{2 , 0 4 6 2}$ & $\mathbf{0 , 0 4 6 1}$ \\
\hline NOREPEAT & $\mathbf{0 , 2 5 7 4}$ & $\mathbf{3 , 6 0 0 4}$ & $\mathbf{0 , 0 0 0 5}$ \\
\hline PRERECORD & 0,1751 & 1,7866 & 0,0777 \\
\hline HOURS & $\mathbf{0 , 2 3 1 5}$ & $\mathbf{2 , 8 5 3 2}$ & $\mathbf{0 , 0 0 5 5}$ \\
\hline STUDY & 0,0617 & 0,2822 & 0,7785 \\
\hline ASISSTENCE & 0,1055 & 1,2469 & 0,2159 \\
\hline ASPIRATION & $\mathbf{0 , 3 7 4 7}$ & $\mathbf{5 , 1 9 5 9}$ & $\mathbf{0 , 0 0 0 0}$ \\
\hline SELFCONFIDENCE & 0,1649 & 1,3592 & 0,1778 \\
\hline PARENTSCONFIDENCE & $\mathbf{0 , 2 2 6 2}$ & $\mathbf{2 , 2 0 8 0}$ & $\mathbf{0 , 0 3 0 0}$ \\
\hline TEACHERSCONFIDENCE & $-0,2024$ & $-1,2283$ & 0,2228 \\
\hline PARandTEACHCONFIDENCE & 0,1878 & 1,7437 & 0,0849 \\
\hline INCOMES & $\mathbf{0 , 1 8 2 8}$ & $\mathbf{2 , 0 2 1 4}$ & $\mathbf{0 , 0 4 6 5}$ \\
\hline FATHEREDUC & $\mathbf{0 , 2 1 0 7}$ & $\mathbf{2 , 0 5 7 7}$ & $\mathbf{0 , 0 4 2 8}$ \\
\hline MOTHEREDUC & $\mathbf{0 , 2 8 6 0}$ & $\mathbf{2 , 6 6 6 6}$ & $\mathbf{0 , 0 0 9 2}$ \\
\hline FATHERJOB & $\mathbf{0 , 1 6 3 4}$ & $\mathbf{2 , 6 1 2 5}$ & $\mathbf{0 , 0 1 0 7}$ \\
\hline MOTHERJOB & $\mathbf{0 , 2 9 6 4}$ & $\mathbf{3 , 2 8 0 8}$ & $\mathbf{0 , 0 0 1 5}$ \\
\hline GRANT & $\mathbf{0 , 2 9 3 2}$ & $\mathbf{3 , 6 9 2 7}$ & $\mathbf{0 , 0 0 0 4}$ \\
\hline ONLYCHILD & 0,1432 & 0,5494 & 0,5842 \\
\hline CHANGESCHOOL & 0,0595 & 0,5125 & 0,6097 \\
\hline UNIVERSITY & $\mathbf{0 , 1 5 3 1}$ & 1,3599 & 0,1775 \\
\hline \hline
\end{tabular}


Table 3. Individual regressions with "MARKS" as dependent variable

\begin{tabular}{||c|r|r|r|}
\hline & COEFICIENTE & ESTADISTICO T & \multicolumn{1}{|c|}{ PROB. } \\
\hline SEX & 0,0214 & 0,4905 & 0,6251 \\
\hline PASSALL & 0,1078 & 3,1346 & 0,0024 \\
\hline RECORD & 0,1178 & 2,7311 & 0,0077 \\
\hline NOREPEAT & 0,1203 & 3,6811 & 0,0004 \\
\hline PRERECORD & 0,1378 & 3,1865 & 0,0020 \\
\hline HOURS & 0,0867 & 2,2919 & 0,0244 \\
\hline STUDY & 0,1963 & 2,0044 & 0,0483 \\
\hline ASISSTENCE & $-0,0246$ & $-0,6298$ & 0,5306 \\
\hline ASPIRATION & 0,1250 & 3,5204 & 0,0007 \\
\hline SELFCONFIDENCE & 0,1675 & 3,1484 & 0,0023 \\
\hline PARENTSCONFIDENCE & 0,1347 & 2,9265 & 0,0044 \\
\hline TEACHERSCONFIDENCE & 0,0839 & 1,1076 & 0,2713 \\
\hline PARandTEACHCONFIDENCE & 0,1433 & 2,9991 & 0,0036 \\
\hline INCOMES & 0,1706 & 4,4742 & 0,0000 \\
\hline FATHEREDUC & 0,1901 & 4,3815 & 0,0000 \\
\hline MOTHEREDUC & 0,1772 & 3,7358 & 0,0003 \\
\hline FATHERJOB & 0,1004 & 3,6197 & 0,0005 \\
\hline MOTHERJOB & 0,1486 & 3,6321 & 0,0005 \\
\hline GRANT & 0,1476 & 4,1243 & 0,0001 \\
\hline ONLYCHILD & 0,0851 & 0,7130 & 0,4778 \\
\hline CHANGESCHOOL & $-0,0568$ & $-1,0730$ & 0,2864 \\
\hline UNIVERSITY & 0,0775 & 1,5042 & 0,1363 \\
\hline
\end{tabular}

Table 4. Pearson correlation coefficient amongst significant variables

\begin{tabular}{|c|c|c|c|c|c|c|c|c|c|c|c|}
\hline & PALL & REC & NOREP & PACNF & ASPIR & INC & FAEDU & MOEDU & FAJOB & MOJOB & GRAN7 \\
\hline PASSALL & 1,000 & & & & & & & & & & \\
\hline RECORD & $0,679^{*}$ & 1,000 & & & & (av & & & & & \\
\hline NOREPEAT & $0,602^{*}$ & $0,595^{*}$ & 1,000 & & & & $\theta$ & & & & \\
\hline PARCONFID & 0,172 & 0,232 & 0,266 & 1,000 & & & 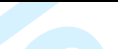 & & & & \\
\hline ASPIRAT & $0,527^{*}$ & $0,367^{*}$ & $0,463^{*}$ & $0,303^{*}$ & 1,000 & & 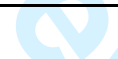 & & & & \\
\hline INCOMES & 0,250 & 0,196 & 0,205 & 0,104 & $0,277^{*}$ & 1,000 & 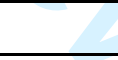 & 0 & & & \\
\hline FATEDUC & 0,288 & 0,266 & 0,253 & 0,226 & $0,330^{*}$ & $0,830^{*}$ & 1,000 & 2 & & & \\
\hline MOTEDUC & $0,335^{\star}$ & $0,318^{*}$ & 0,203 & 0,169 & $0,317^{\star}$ & $0,790^{*}$ & $0,882^{*}$ & 1,000 & & & \\
\hline FATJOB & 0,198 & 0,088 & 0,150 & 0,120 & $0,314^{*}$ & $0,790^{*}$ & $0,814^{\star}$ & $0,766^{*}$ & 1,000 & & \\
\hline МОТЈOВ & 0,219 & 0,152 & 0,157 & 0,205 & 0,265 & $0,775^{\star}$ & $0,776^{*}$ & $0,843^{*}$ & $0,788^{*}$ & 1,000 & \\
\hline GRANT & $0,511^{*}$ & $0,398^{*}$ & $0,467^{\star}$ & $0,381^{*}$ & $0,624^{*}$ & $0,412^{*}$ & $0,441^{*}$ & $0,416^{*}$ & $0,429^{*}$ & $0,414^{*}$ & 1,000 \\
\hline
\end{tabular}

*Significant correlation at 0,01 . 
Table 5: Principal Components Analysis for non-discretionary inputs

\begin{tabular}{|c|c|c|c|c|c|c|}
\hline & \multicolumn{3}{|c|}{ Initial Eigenvalues } & \multicolumn{3}{|c|}{$\begin{array}{c}\text { Extraction Sums of Squared } \\
\text { Loadings }\end{array}$} \\
\hline Component & Total & \begin{tabular}{c|}
$\%$ of \\
variance
\end{tabular} & $\begin{array}{c}\text { Cumulative } \\
\%\end{array}$ & Total & $\begin{array}{c}\% \text { of } \\
\text { variance }\end{array}$ & $\begin{array}{c}\text { Cumulative } \\
\%\end{array}$ \\
\hline 1 & 5.145 & 46.777 & 46.777 & 5.145 & 46.777 & 46.777 \\
\hline 2 & 2.364 & 21.489 & 68.265 & 2.364 & 21.489 & 68.265 \\
\hline 3 & 1.092 & 9.927 & 78.192 & 1.092 & 9.927 & 78.192 \\
\hline 4 & .665 & 6.048 & 84.241 & & & \\
\hline 5 & .459 & 4.169 & 88.409 & & & \\
\hline 6 & .371 & 3.373 & 91.782 & & & \\
\hline 7 & .271 & 2.465 & 94.247 & & & \\
\hline 8 & .208 & 1.887 & 96.135 & & & \\
\hline 9 & .193 & 1.757 & 97.892 & & & \\
\hline 10 & .152 & 1.381 & 99.273 & & & \\
\hline 11 & .079 & .727 & 100.000 & & & \\
\hline
\end{tabular}

Table 6: Rotated Factor Matrix (PCA)

\begin{tabular}{||c|r|r|r||}
\hline & \multicolumn{3}{|c|}{ COMPONENT } \\
\hline & $\mathbf{1}$ & $\mathbf{2}$ & $\mathbf{3}$ \\
\hline PASSALL & 0.107 & $\mathbf{0 . 7 8 0}$ & 0.374 \\
\hline NOREPEAT & 0.072 & $\mathbf{0 . 6 9 0}$ & 0.482 \\
\hline RECORD & 0.085 & $\mathbf{0 . 8 8 3}$ & 0.126 \\
\hline HOURS & 0.057 & 0.088 & $\mathbf{0 . 9 0 9}$ \\
\hline ASPIRATION & 0.255 & 0.416 & $\mathbf{0 . 5 0 5}$ \\
\hline CONFIDENCE & 0.274 & $\mathbf{0 . 7 7 3}$ & -0.194 \\
\hline INCOMES & $\mathbf{0 . 8 8 8}$ & 0.112 & 0.166 \\
\hline FATHEREDUC & $\mathbf{0 . 9 1 5}$ & 0.205 & 0.037 \\
\hline MOTHEREDUC & $\mathbf{0 . 9 1 6}$ & 0.250 & -0.042 \\
\hline FATHERJOB & $\mathbf{0 . 8 9 9}$ & 0.020 & 0.190 \\
\hline MOTHERJOB & $\mathbf{0 . 9 0 1}$ & 0.114 & 0.049 \\
\hline \hline
\end{tabular}

Rotation Method: Varimax with Kaiser Normalization. 
Table 7: Efficiency scores and rankings

\begin{tabular}{|c|c|c|c|c|c|c|}
\hline & Standard DEA & Rank & SW Model & Rank & $\begin{array}{l}\text { 4-Stages Model } \\
\text { with bootstrap }\end{array}$ & Rank \\
\hline HS 1 & 1,166 & 46 & 1,1693 & 36 & 1,078 & 25 \\
\hline HS 2 & 1,236 & 71 & 1,2029 & 67 & 1,126 & 47 \\
\hline HS 3 & 1,128 & 26 & 1,1471 & 25 & 1,117 & 44 \\
\hline HS 4 & 1,241 & 72 & 1,2097 & 71 & 1,174 & 70 \\
\hline HS 5 & 1,158 & 39 & 1,1729 & 42 & 1,104 & 38 \\
\hline HS 6 & 1,098 & 19 & 1,1239 & 17 & 1,110 & 41 \\
\hline HS 7 & 1,149 & 33 & 1,1696 & 38 & 1,171 & 69 \\
\hline HS 8 & 1,065 & 11 & 1,0916 & 6 & 1,063 & 20 \\
\hline HS 9 & 1,142 & 30 & 1,1548 & 26 & 1,084 & 27 \\
\hline HS 10 & 1,300 & 79 & 1,2201 & 79 & 1,215 & 77 \\
\hline HS 11 & 1,076 & 14 & 1,0974 & 10 & 1,138 & 54 \\
\hline HS 12 & 1,000 & 4 & 1,0950 & 7 & 1,000 & 2 \\
\hline HS 13 & 1,221 & 67 & 1,2018 & 65 & 1,156 & 61 \\
\hline HS 14 & 1,204 & 59 & 1,1913 & 56 & 1,159 & 64 \\
\hline HS 15 & 1,246 & 74 & 1,2076 & 69 & 1,160 & 65 \\
\hline HS 16 & 1,150 & 34 & 1,1798 & 47 & 1,127 & 48 \\
\hline HS 17 & 1,077 & 15 & 1,1263 & 18 & 1,038 & 14 \\
\hline HS 18 & 1,000 & 5 & 1,0972 & 8 & 1,000 & 8 \\
\hline HS 19 & 1,201 & 56 & 1,1998 & 63 & 1,099 & 37 \\
\hline HS 20 & 1,151 & 35 & 1,1608 & 29 & 1,215 & 76 \\
\hline HS 21 & 1,173 & 51 & 1,1732 & 43 & 1,077 & 24 \\
\hline HS 22 & 1,110 & 22 & 1,1321 & 22 & 1,000 & 5 \\
\hline HS 23 & 1,206 & 63 & 1,1952 & 59 & 1,156 & 60 \\
\hline HS 24 & 1,000 & 2 & 1,0443 & 2 & 1,070 & 21 \\
\hline HS 25 & 1,065 & 10 & 1,0973 & 9 & 1,000 & 10 \\
\hline HS 26 & 1,164 & 45 & 1,1865 & 52 & 1,105 & 39 \\
\hline HS 27 & 1,154 & 37 & 1,1870 & 53 & 1,099 & 36 \\
\hline HS 28 & 1,173 & 49 & 1,1759 & 45 & 1,037 & 13 \\
\hline HS 29 & 1,169 & 47 & 1,1722 & 41 & 1,136 & 53 \\
\hline HS 30 & 1,190 & 54 & 1,1847 & 51 & 1,113 & 42 \\
\hline HS 31 & 1,000 & 8 & 1,0805 & 5 & 1,000 & 11 \\
\hline HS 32 & 1,144 & 31 & 1,1780 & 46 & 1,092 & 29 \\
\hline HS 33 & 1,160 & 40 & 1,1695 & 37 & 1,039 & 15 \\
\hline HS 34 & 1,099 & 20 & 1,1271 & 19 & 1,000 & 9 \\
\hline HS 35 & 1,161 & 41 & 1,1705 & 39 & 1,098 & 35 \\
\hline HS 36 & 1,206 & 64 & 1,1913 & 57 & 1,046 & 16 \\
\hline HS 37 & 1,307 & 80 & 1,2173 & 77 & 1,248 & 79 \\
\hline HS 38 & 1,146 & 32 & 1,1683 & 35 & 1,094 & 33 \\
\hline HS 39 & 1,182 & 52 & 1,2139 & 74 & 1,125 & 46 \\
\hline HS 40 & 1,162 & 43 & 1,1672 & 32 & 1,134 & 51 \\
\hline HS 41 & 1,196 & 55 & 1,1812 & 49 & 1,115 & 43 \\
\hline HS 42 & 1,085 & 17 & 1,1625 & 30 & 1,000 & 4 \\
\hline HS 43 & 1,108 & 21 & 1,1312 & 21 & 1,055 & 18 \\
\hline HS 44 & 1,000 & 1 & 1,1151 & 14 & 1,000 & 1 \\
\hline
\end{tabular}




\begin{tabular}{||c|c|c|c|c|c|c||}
\hline HS 45 & $\mathbf{1 , 0 8 7}$ & 18 & $\mathbf{1 , 1 1 8 1}$ & $\mathbf{1 5}$ & $\mathbf{1 , 0 5 2}$ & 17 \\
\hline HS 46 & $\mathbf{1 , 2 0 6}$ & 61 & $\mathbf{1 , 2 1 4 5}$ & $\mathbf{7 5}$ & $\mathbf{1 , 1 6 7}$ & 68 \\
\hline HS 47 & $\mathbf{1 , 1 1 3}$ & 23 & $\mathbf{1 , 1 3 0 8}$ & $\mathbf{2 0}$ & $\mathbf{1 , 1 0 7}$ & 40 \\
\hline HS 48 & $\mathbf{1 , 2 5 5}$ & 77 & $\mathbf{1 , 2 1 7 2}$ & $\mathbf{7 6}$ & $\mathbf{1 , 1 8 2}$ & 71 \\
\hline HS 49 & $\mathbf{1 , 2 2 6}$ & 68 & $\mathbf{1 , 1 9 9 5}$ & $\mathbf{6 1}$ & $\mathbf{1 , 2 5 9}$ & 80 \\
\hline HS 50 & $\mathbf{1 , 1 6 2}$ & 42 & $\mathbf{1 , 1 7 0 9}$ & $\mathbf{4 0}$ & $\mathbf{1 , 2 0 3}$ & 74 \\
\hline HS 51 & $\mathbf{1 , 1 7 3}$ & 50 & $\mathbf{1 , 1 8 1 4}$ & $\mathbf{5 0}$ & $\mathbf{1 , 1 5 1}$ & 59 \\
\hline HS 52 & $\mathbf{1 , 0 0 0}$ & 6 & $\mathbf{1 , 0 5 3 3}$ & $\mathbf{3}$ & $\mathbf{1 , 0 0 0}$ & 7 \\
\hline HS 53 & $\mathbf{1 , 2 5 4}$ & 76 & $\mathbf{1 , 2 1 0 9}$ & $\mathbf{7 3}$ & $\mathbf{1 , 1 6 1}$ & 67 \\
\hline HS 54 & $\mathbf{1 , 1 2 0}$ & 24 & $\mathbf{1 , 1 4 2 2}$ & $\mathbf{2 3}$ & $\mathbf{1 , 0 7 9}$ & 26 \\
\hline HS 55 & $\mathbf{1 , 1 3 5}$ & 28 & $\mathbf{1 , 1 5 8 7}$ & $\mathbf{2 8}$ & $\mathbf{1 , 0 9 4}$ & 31 \\
\hline HS 56 & $\mathbf{1 , 0 0 0}$ & 7 & $\mathbf{1 , 0 4 0 2}$ & $\mathbf{1}$ & $\mathbf{1 , 0 0 0}$ & 6 \\
\hline HS 57 & $\mathbf{1 , 1 5 4}$ & 38 & $\mathbf{1 , 1 6 3 1}$ & $\mathbf{3 1}$ & $\mathbf{1 , 0 9 6}$ & 34 \\
\hline HS 58 & $\mathbf{1 , 1 3 3}$ & 27 & $\mathbf{1 , 2 0 9 7}$ & $\mathbf{7 2}$ & $\mathbf{1 , 0 8 8}$ & 28 \\
\hline HS 59 & $\mathbf{1 , 0 7 5}$ & 13 & $\mathbf{1 , 1 0 3 3}$ & $\mathbf{1 1}$ & $\mathbf{1 , 1 5 9}$ & 63 \\
\hline HS 60 & $\mathbf{1 , 2 0 2}$ & 58 & $\mathbf{1 , 1 9 9 0}$ & $\mathbf{6 0}$ & $\mathbf{1 , 0 7 6}$ & 23 \\
\hline HS 61 & $\mathbf{1 , 1 8 3}$ & 53 & $\mathbf{1 , 1 8 0 3}$ & $\mathbf{4 8}$ & $\mathbf{1 , 2 1 6}$ & 78 \\
\hline HS 62 & $\mathbf{1 , 2 4 3}$ & 73 & $\mathbf{1 , 2 0 5 1}$ & $\mathbf{6 8}$ & $\mathbf{1 , 1 3 2}$ & 50 \\
\hline HS 63 & $\mathbf{1 , 1 7 0}$ & 48 & $\mathbf{1 , 1 7 3 9}$ & $\mathbf{4 4}$ & $\mathbf{1 , 1 3 5}$ & 52 \\
\hline HS 64 & $\mathbf{1 , 2 5 9}$ & 78 & $\mathbf{1 , 2 1 8 7}$ & $\mathbf{7 8}$ & $\mathbf{1 , 1 9 5}$ & 73 \\
\hline HS 65 & $\mathbf{1 , 2 0 2}$ & 57 & $\mathbf{1 , 1 9 4 2}$ & $\mathbf{5 8}$ & $\mathbf{1 , 1 4 2}$ & 56 \\
\hline HS 66 & $\mathbf{1 , 2 4 8}$ & 75 & $\mathbf{1 , 2 0 8 9}$ & $\mathbf{7 0}$ & $\mathbf{1 , 2 0 8}$ & 75 \\
\hline HS 67 & $\mathbf{1 , 1 5 2}$ & 36 & $\mathbf{1 , 1 6 8 2}$ & $\mathbf{3 4}$ & $\mathbf{1 , 1 2 4}$ & 45 \\
\hline HS 68 & $\mathbf{1 , 2 3 1}$ & 70 & $\mathbf{1 , 2 0 2 3}$ & $\mathbf{6 6}$ & $\mathbf{1 , 1 3 1}$ & 49 \\
\hline HS 69 & $\mathbf{1 , 1 9 5}$ & 55 & $\mathbf{1 , 1 9 0 1}$ & $\mathbf{5 4}$ & $\mathbf{1 , 1 4 7}$ & 58 \\
\hline HS 70 & $\mathbf{1 , 2 2 1}$ & 66 & $\mathbf{1 , 1 9 9 7}$ & $\mathbf{6 2}$ & $\mathbf{1 , 1 5 8}$ & 62 \\
\hline HS 71 & $\mathbf{1 , 0 0 0}$ & 3 & $\mathbf{1 , 1 0 8 7}$ & $\mathbf{1 2}$ & $\mathbf{1 , 0 0 0}$ & 3 \\
\hline HS 72 & $\mathbf{1 , 2 0 4}$ & 60 & $\mathbf{1 , 1 9 0 2}$ & $\mathbf{5 5}$ & $\mathbf{1 , 1 3 7}$ & 55 \\
\hline HS 73 & $\mathbf{1 , 2 2 9}$ & 69 & $\mathbf{1 , 2 0 1 5}$ & $\mathbf{6 4}$ & $\mathbf{1 , 1 4 5}$ & 57 \\
\hline HS 74 & $\mathbf{1 , 0 7 9}$ & 16 & $\mathbf{1 , 1 0 9 3}$ & $\mathbf{1 3}$ & $\mathbf{1 , 0 7 5}$ & 22 \\
\hline HS 75 & $\mathbf{1 , 1 2 6}$ & 25 & $\mathbf{1 , 1 4 6 9}$ & $\mathbf{2 4}$ & $\mathbf{1 , 0 5 8}$ & 19 \\
\hline HS 76 & $\mathbf{1 , 2 1 7}$ & 65 & $\mathbf{1 , 2 3 3 0}$ & $\mathbf{8 0}$ & $\mathbf{1 , 1 9 3}$ & 72 \\
\hline HS 77 & $\mathbf{1 , 1 6 3}$ & 44 & $\mathbf{1 , 1 6 7 6}$ & $\mathbf{3 3}$ & $\mathbf{1 , 0 9 3}$ & 30 \\
\hline HS 78 & $\mathbf{1 , 0 4 3}$ & 9 & $\mathbf{1 , 0 7 2 7}$ & $\mathbf{4}$ & $\mathbf{1 , 0 0 0}$ & 12 \\
\hline HS 79 & $\mathbf{1 , 0 6 8}$ & 12 & $\mathbf{1 , 1 1 9 0}$ & $\mathbf{1 6}$ & $\mathbf{1 , 1 6 0}$ & 66 \\
\hline HS 80 & $\mathbf{1 , 1 4 1}$ & 29 & $\mathbf{1 , 1 5 7 6}$ & $\mathbf{2 7}$ & $\mathbf{1 , 0 9 4}$ & 32 \\
\hline Hverage & $\mathbf{1 , 1 5 0}$ & - & $\mathbf{1 , 1 6 2 5}$ & - & $\mathbf{1 , 1 0 8}$ & - \\
\hline
\end{tabular}


Table 8: Non-discretionary inputs for each high school

\begin{tabular}{|c|c|c|c|c|c|c|c|}
\hline & PC1 & PC2 & PC3 & & PC1 & PC2 & PC3 \\
\hline HS 1 & 1.0808 & 1.4951 & 1.0187 & HS 41 & 0.2187 & 2.7987 & 2.3335 \\
\hline HS 2 & 1.4212 & 0.6059 & 0.1967 & HS 42 & 0.6686 & 2.1311 & 2.1477 \\
\hline HS 3 & 1.8614 & 3.1401 & 2.1468 & HS 43 & 0.3599 & 3.7343 & 2.2877 \\
\hline HS 4 & 0.7276 & 2.7477 & 2.0753 & HS 44 & 1.9076 & 1.8234 & 2.4579 \\
\hline HS 5 & 1.4026 & 3.1588 & 1.3687 & HS 45 & 1.1824 & 4.3392 & 1.3264 \\
\hline HS 6 & 1.9669 & 2.4983 & 3.4984 & HS 46 & 0.3398 & 3.6254 & 2.7528 \\
\hline HS 7 & 2.2588 & 2.6491 & 3.1852 & HS 47 & 1.0450 & 3.9637 & 1.8646 \\
\hline HS 8 & 0.8083 & 2.3982 & 5.2743 & HS 48 & 0.3185 & 3.4848 & 0.6267 \\
\hline HS 9 & 0.6896 & 3.2240 & 3.3473 & HS 49 & 1.0532 & 4.0855 & 2.9011 \\
\hline HS 10 & 0.4224 & 1.8592 & 1.4136 & HS 50 & 2.0677 & 4.3398 & 1.3995 \\
\hline HS 11 & 4.6013 & 1.0401 & 2.0900 & HS 51 & 1.4411 & 2.7152 & 2.2873 \\
\hline HS 12 & 1.3850 & 3.9275 & 2.4113 & HS 52 & 3.1948 & 3.6682 & 1.6367 \\
\hline HS 13 & 0.0000 & 3.3721 & 2.1315 & HS 53 & 0.5786 & 1.7482 & 1.7943 \\
\hline HS 14 & 1.5857 & 2.0269 & 1.3725 & HS 54 & 1.2085 & 2.6764 & 2.2443 \\
\hline HS 15 & 1.0413 & 0.6457 & 2.3220 & HS 55 & 1.3972 & 2.8984 & 2.3295 \\
\hline HS 16 & 0.9165 & 4.4271 & 1.5982 & HS 56 & 3.6352 & 5.0613 & 1.6067 \\
\hline HS 17 & 1.3560 & 3.8398 & 1.4263 & HS 57 & 0.9291 & 3.0304 & 1.1858 \\
\hline HS 18 & 2.4432 & 2.3563 & 1.7231 & HS 58 & 1.5084 & 2.2075 & 1.4870 \\
\hline HS 19 & 0.2991 & 3.2500 & 0.2965 & HS 59 & 4.4237 & 2.5879 & 2.4581 \\
\hline HS 20 & 2.5508 & 2.6287 & 4.0942 & HS 60 & 1.4312 & 1.8256 & 1.9502 \\
\hline HS 21 & 0.5152 & 2.7861 & 1.1598 & HS 61 & 1.9006 & 3.7419 & 1.8804 \\
\hline HS 22 & 0.3016 & 3.1860 & 1.6239 & HS 62 & 0.9679 & 1.1688 & 0.0288 \\
\hline HS 23 & 0.5144 & 2.4602 & 3.0751 & HS 63 & 0.5758 & 3.5621 & 2.3229 \\
\hline HS 24 & 3.5859 & 3.3580 & 2.3960 & HS 64 & 0.9592 & 2.4005 & 1.2170 \\
\hline HS 25 & 0.5770 & 2.6935 & 3.0344 & HS 65 & 0.8750 & 3.1157 & 1.0487 \\
\hline HS 26 & 0.8750 & 2.3512 & 2.2104 & HS 66 & 1.4877 & 0.6579 & 3.1975 \\
\hline HS 27 & 1.0462 & 3.4355 & 1.1760 & HS 67 & 1.8478 & 2.4793 & 1.4155 \\
\hline HS 28 & 0.7177 & 0.0000 & 1.2093 & HS 68 & 0.2757 & 2.8287 & 0.0000 \\
\hline HS 29 & 0.4964 & 3.1566 & 2.4382 & HS 69 & 2.4651 & 1.9489 & 0.1295 \\
\hline HS 30 & 1.2993 & 3.0063 & 0.5576 & HS 70 & 0.0480 & 2.0493 & 3.7129 \\
\hline HS 31 & 2.0975 & 3.5235 & 2.1756 & HS 71 & 1.4361 & 2.8011 & 2.0229 \\
\hline HS 32 & 0.0925 & 3.0095 & 3.6040 & HS 72 & 0.9623 & 1.6753 & 2.2555 \\
\hline HS 33 & 0.1048 & 2.8841 & 0.9020 & HS 73 & 1.0699 & 2.1929 & 0.4935 \\
\hline HS 34 & 0.8876 & 1.5343 & 2.9837 & HS 74 & 2.6558 & 3.1612 & 2.0677 \\
\hline HS 35 & 1.5845 & 2.1841 & 1.3469 & HS 75 & 0.9686 & 2.0025 & 2.8209 \\
\hline HS 36 & 0.5419 & 0.7101 & 0.1403 & HS 76 & 0.8843 & 4.7554 & 0.3874 \\
\hline HS 37 & 0.7452 & 1.6108 & 2.3759 & HS 77 & 1.6583 & 1.4129 & 1.2149 \\
\hline HS 38 & 2.0752 & 3.1690 & 0.9027 & HS 78 & 0.1629 & 3.6564 & 1.9776 \\
\hline HS 39 & 0.2346 & 3.4821 & 2.6125 & HS 79 & 3.7948 & 2.3542 & 2.1048 \\
\hline HS 40 & 0.6136 & 2.7154 & 2.5032 & HS 80 & 2.7672 & 2.1222 & 0.4030 \\
\hline Average & 1.3050 & 2.6922 & 1.8900 & Average & 1.3050 & 2.6922 & 1.8900 \\
\hline
\end{tabular}

